\title{
Clinical utility gene card for: blue cone monochromatism
}

\author{
Susanne Kohl ${ }^{\star 1}$ and Christian P Hamel ${ }^{2}$ \\ European Journal of Human Genetics (2011) 19, doi:10.1038/ejhg.2010.232; published online 26 January 2011
}

\section{DISEASE CHARACTERISTICS}

1.1 Name of the disease (synonyms)

Blue cone monochromatism (BCM); colour blindness, blue-monocone-monochromatic type (CBBM).

\subsection{OMIM\# of the disease}

303700 .

1.3 Name of the analysed genes or DNA/chromosome segments OPN1LW/OPNMW gene cluster on the X-chromosome, Chr. Xq28.

1.4 OMIM\# of the gene(s)

OPN1LW, RCP, CBP; 303900, OPN1MW, GCP, CBD; 303800.

\subsection{Mutational spectrum}

Large deletions spanning the locus control region and/or the promoters and/or the genes; genomic rearrangements - inequal crossing-over, resulting in single red and/or red/green hybrid genes; inactivating missense mutations (most common missense mutation c.607T $>\mathrm{C}$ p.C203R). ${ }^{1,2}$

\subsection{Analytical methods}

Duplex PCRs, PCR/RFLP defining the structure and integrity of the OPN1LWIOPN1MW gene cluster, DNA sequencing for point mutations.

\subsection{Analytical validation}

Confirmation of mutation in an independent biological sample of the index case and/or in an affected subject.

In case of a genomic deletion, confirmation by duplex PCR and/or second technique; if possible define breakpoints by longdistance PCR.

\subsection{Estimated frequency of the disease}

(incidence at birth ('birth prevalence') or population prevalence): 1:100 000 .

1.9 If applicable, prevalence in the ethnic group of investigated person

Unknown.
1.10 Diagnostic setting

\begin{tabular}{lll}
\hline & Yes & No \\
\hline A. (Differential) diagnostics & $\Downarrow$ & $\square$ \\
B. Predictive testing & $\square$ & $\square$ \\
C. Risk assessment in relatives & $\bigotimes$ & $\square$ \\
D. Prenatal & $\bigotimes$ & $\square$ \\
\hline
\end{tabular}

Comment:

As penetrance is $100 \%$ and since disease is present from birth, the test is not used for predictive testing.

\section{TEST CHARACTERISTICS}

\begin{tabular}{|c|c|c|c|c|}
\hline & \multicolumn{2}{|c|}{ Genotype or disease } & \multirow{2}{*}{$\begin{array}{l}\text { A: True positives } \\
\text { B: False positives }\end{array}$} & \multirow{2}{*}{$\begin{array}{l}\text { C: False negatives } \\
\text { D: True negatives }\end{array}$} \\
\hline & Present & Absent & & \\
\hline \multicolumn{5}{|l|}{ Test } \\
\hline \multirow[t]{2}{*}{ Positive } & $A$ & $\mathrm{~B}$ & Sensitivity: & $A /(A+C)$ \\
\hline & & & Specificity: & $D /(D+B)$ \\
\hline \multirow[t]{2}{*}{ Negative } & $\mathrm{C}$ & $\mathrm{D}$ & Positive predictive value: & $A /(A+B)$ \\
\hline & & & Negative predictive value: & $\mathrm{D} /(\mathrm{C}+\mathrm{D})$ \\
\hline
\end{tabular}

2.1 Analytical sensitivity

(proportion of positive tests if the genotype is present) Over $90 \%$.

2.2 Analytical specificity (proportion of negative tests if the genotype is not present) Above 95\%.

2.3 Clinical sensitivity (proportion of positive tests if the disease is present)

The clinical sensitivity can be dependent on variable factors such as age or family history. In such cases, a general statement should be given, even if a quantification can only be made case by case.

Above $90 \%$.

\footnotetext{
${ }^{1}$ Molecular Genetics Laboratory, Institute for Ophthalmic Research, Centre for Opthalmology, University Tuebingen, Tuebingen, Germany; ${ }^{2}$ Genetics and therapy of retinal and optic nerve blindness, INSERM U583, Institut des Neurosciences, Montpellier, France

*Correspondence: Dr S Kohl, Molecular Genetics Laboratory, Institute for Ophthalmic Research, Centre for Opthalmology, University Tuebingen, Roentgenweg 11, 72076, Tuebingen, Germany. Tel: +49 707129 80702; Fax: +49 707129 5725; E-mail: Susanne.kohl@uni-tuebingen.de
} 
2.4 Clinical specificity

(proportion of negative tests if the disease is not present)

The clinical specificity can be dependent on variable factors such as age or family history. In such cases, a general statement should be given, even if a quantification can only be made case by case.

Above 95\%.

2.5 Positive clinical predictive value (life-time risk to develop the disease if the test is positive)

Nearly $100 \%$ penetrance with little variability in disease expression (macular degeneration and rarely progression is observed ${ }^{3,4}$ ).

2.6 Negative clinical predictive value (probability not to develop the disease if the test is negative) Assume an increased risk based on family history for a nonaffected person. Allelic and locus heterogeneity may need to be considered.

Index case in that family had been tested:

Nearly $100 \%$ if genotype identified in index case. Mutations and rearrangements in the OPN1LWIOPN1MW gene cluster and locus control region are the only cause of BCM.

Carriership testing in female family members is limited.

Index case in that family had not been tested:

This approach cannot be supported.

\section{CLINICAL UTILITY}

3.1 (Differential) diagnosis: the tested person is clinically affected (To be answered if in 1.10 'A' was marked)

\subsubsection{Can a diagnosis be made other than through a genetic test?}

\begin{tabular}{lll}
\hline No & $\square$ (continue with 3.1.4) \\
Yes & $\bigotimes$ & \\
& Clinically. & \\
Imaging. & $\square$ \\
& Endoscopy. \\
& Biochemistry. \\
& Electrophysiology. \\
& Other (please describe): \\
& Comment: \\
& Standard clinical ophthalmological evaluation and testing \\
& Electrophysiological examination (electroretinography) \\
& Psychophysical testings (colour vision, dark adaptometry) \\
& \\
\end{tabular}

3.1.2 Describe the burden of alternative diagnostic methods to the patient

Initial clinical and electrophysiological investigations are always necessary before molecular genetic analysis is prescribed. However, clinical investigations are sometimes incomplete in young children (approximate visual acuity, ERG recorded with skin electrodes and/or handheld, non-Ganzfeld stimulator). Complete clinical investigations and ERG recording may require general anaesthesia.

\subsubsection{How is the cost effectiveness of alternative diagnostic methods to be judged?}

Clinical and electrophysiological testing in young children may require anaesthesia and hospitalisation.
3.1.4 Will disease management be influenced by the result of a genetic test?

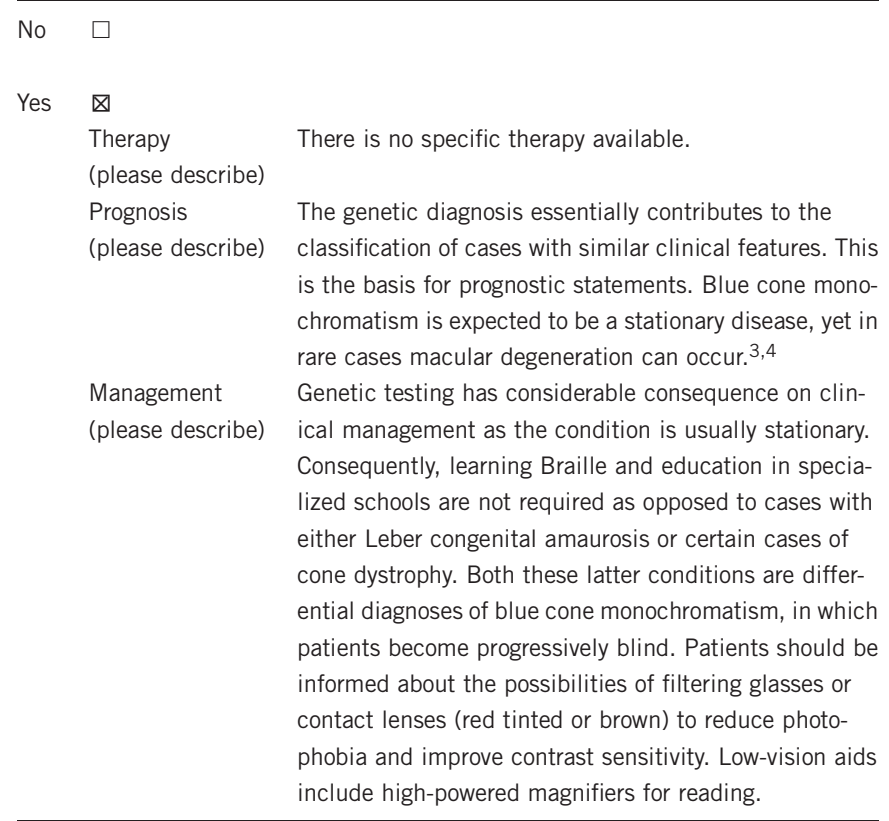

3.2 Predictive setting: the tested person is clinically unaffected but carries an increased risk based on family history

(To be answered if in 1.10 ' $\mathrm{B}$ ' was marked)

\subsubsection{Will the result of a genetic test influence lifestyle and preven-} tion?

If the test result is positive (please describe):

Genetic analysis can guide prospective parents concerned about the risk of having affected children and will help in management of the disease in affected patients (see 3.1.4).

If the test result is negative (please describe):

This will lead to reconsider the clinical diagnosis. The diagnosis of blue cone monochromatism will therefore be either confirmed, or excluded and redirected to achromatopsia, for example.

3.2.2 Which options in view of lifestyle and prevention does a person at-risk have if no genetic test has been done (please describe)?

Regular ophthalmological follow-up examination.

3.3 Genetic risk assessment in family members of a diseased person (To be answered if in 1.10 ' $\mathrm{C}$ ' was marked)

3.3.1 Does the result of a genetic test resolve the genetic situation in that family?

Yes, X-linked inheritance.

3.3.2 Can a genetic test in the index patient save genetic or other tests in family members?

No.

3.3.3 Does a positive genetic test result in the index patient enable a predictive test in a family member?

Yes, for recurrence risk and female carriers. 
3.4 Prenatal diagnosis

(To be answered if in 1.10 'D' was marked)

3.4.1 Does a positive genetic test result in the index patient enable a prenatal diagnostic?

Genetic counselling is mandatory. Prenatal diagnosis is increasingly asked by at-risk couples and use of prenatal diagnostic test varies with national/ethical customs.

\section{IF APPLICABLE, FURTHER CONSEQUENCES OF TESTING}

Please assume that the result of a genetic test has no immediate medical consequences. Is there any evidence that a genetic test is nevertheless useful for the patient or his/her relatives? (Please describe)

Correct diagnosis has implications on education and professional career choices (low vision).

Parents are given accurate information on the cause of the disease, progression and recurrence risk.

\section{CONFLICT OF INTEREST}

The authors declare no conflict of interest.

\section{ACKNOWLEDGEMENTS}

This work was supported by EuroGentest, an EU-FP6 supported NoE, contract number 512148 (EuroGentest unit 3: 'Clinical genetics, community genetics and public health', Workpackage 3.2).

1 Nathans J, Maumenee IH, Zrenner E et al: Genetic heterogeneity among blue-cone monochromats. Am J Hum Genet 1993; 53: 987-1000.

2 Gardner JC, Michaelides M, Holder GE et al: Blue cone monochromacy: causative mutations and associated phenotypes. Mol Vis 2009; 15: 876-884.

3 Kellner U, Wissinger B, Tippmann S, Kohl S, Kraus H, Foerster MH: Blue cone monochromatism: clinical findings in patients with mutations in the red/green opsin gene cluster. Graefes Arch Clin Exp Ophthalmol 2004; 242: 729-735.

4 Michaelides M, Johnson S, Simunovic MP et al: Blue cone monochromatism: a phenotype and genotype assessment with evidence of progressive loss of cone function in older individuals. Eye (Lond) 2005; 19: 2-10. 